\title{
Fibrosing alveolitis in systemic sclerosis: increase in memory T-cells in lung interstitium
}

\author{
A.U. Wells*, S. Lorimer*, S. Majumdar*, N.K. Harrison*, \\ B. Corrin*, C.M. Black**, P.K. Jeffery*, R.M. du Bois*
}

Fibrosing alveolitis in systemic sclerosis: increase in memory T-cells in lung interstitium. A.U. Wells, S. Lorimer, S. Majumdar, N.K. Harrison, B. Corrin, C.M. Black, P.K. Jeffery, R.M. du Bois. CERS Journals Ltd 1995.

ABSTRACT: Despite the large numbers of T-cells present in the lungs in fibrosing alveolitis, their pathogenetic role is poorly understood. If these cells are involved in pathogenesis, they are more likely to express the CD45RO+ memory phenotype. To test this hypothesis, open lung biopsies from patients with fibrosing alveolitis associated with systemic sclerosis (FASSc) were compared with grossly normal lung taken from the periphery of lobes resected for lung cancer.

Biopsies from eight patients with FASSc were compared with tissue from seven cancer controls. Paraffin sections were stained with a polyclonal anti-CD3 antibody for T-lymphocytes, monoclonal anti-CD45 antibody for leucocyte common antigen, and monoclonal anti-CD45RO antibody for primed T-lymphocytes. Staining was assessed quantitatively by computerized image analysis: in each case, the number of immunopositive cells was related to alveolar wall area and alveolar wall length.

Mean alveolar wall thickness was increased in patients with FASSc $(60.7 \pm 24.0$ um) compared with cancer controls $(15.7 \pm 5.3 \mathrm{um})$. Patients with FASSc had greater numbers of $\mathrm{CD45}+, \mathrm{CD3}+$ and $\mathrm{CD} 45 \mathrm{RO}+$ cells $\cdot \mathrm{mm}^{-1}$ alveolar wall length compared with the controls. CD45RO+ cells made up $77 \%$ (median) of the CD3+ cells in FASSc, and their numbers per unit alveolar wall length were positively associated with alveolar wall thickness $(r=0.61)$.

In conclusion, in fibrosing alveolitis of systemic sclerosis, most interstitial $T$ lymphocytes express the phenotype of memory cells; these cells are likely to be involved in the persistent inflammatory process.

Eur Respir J., 1995, 8, 266-271.
*Dept of Lung Pathology and Interstitial Lung Disease Unit, Royal Brompton Hospital, London, UK. **Dept of Rheumatology, Royal Free Hospital, London, UK.

Correspondence: R.M. du Bois Royal Brompton Hospital

Sydney Street

London SW3 6NP

UK

Keywords: Fibrosing alveolitis memory T-cells

systemic sclerosis

Received: December 41993

Accepted after revision November 181994

This study was supported by grants from the Raynaud's and Scleroderma Association, UK and The Scleroderma Federation and the United Scleroderma Foundation, USA.
T-lymphocytes are the predominant interstitial inflammatory cell in fibrosing alveolitis $[1,2]$ but their pathogenetic role is uncertain, although it has been suggested that inflammatory cell infiltration precedes and initiates the fibrotic process [3]. It has been suggested that lymphocytes recruited to the lung may be activated locally [4], and biopsy studies have shown that T-cells at disease sites in fibrosing alveolitis express the activation markers interleukin-2 receptor (IL-2R) and human leucocyte antigen-DR (HLA-DR) [1].

The functional status of T-lymphocytes can be defined by their differential expression of isoforms of the common leucocyte antigen (CD45): the CD45RO isoform, recognized by the monoclonal antibody UCHL1, defines a subpopulation of cells which provide B-cell help, respond preferentially to recall antigen, and have been designated as "memory" cells; whereas, the expression of the CD45R molecule defines the so-called "naive" population [5]. Although it was originally believed that the switch of isoforms from CD45R to CD45RO reflected activation and was unidirectional, this is now disputed $[6,7]$. However, the presence within the lung interstitium of patients with fibrosing alveolitis of large numbers of CD45RO+ T-cells would be consistent with the concept that T-cells at this disease site are better equipped to respond to recall antigens which may play a role in the local immune response.

The aim of the present study was to test the hypothesis that the ongoing inflammation in fibrosing alveolitis may involve the accumulation of this population of cells with enhanced antigen responsiveness. To do this, we examined lung biopsies from patients with fibrosing alveolitis and systemic sclerosis (FASSc), which we have previously shown is identical morphologically to lone cryptogenic fibrosing alveolitis [8]. Our specific objectives were: 1) to quantify inflammatory cells and to determine the proportion of T-cells; 2) to measure the proportion of T-lymphocytes which express the CD45RO+ memory phenotype; and 3 ) to analyse the distribution of memory T-cells with respect to alveolar wall thickness. 


\section{Materials and methods}

\section{Patients}

Open lung biopsies from eight patients (4 males and 4 females) meeting American Rheumatism Association criteria for a diagnosis of systemic sclerosis [9], who were also thought to have fibrosing alveolitis, were studied; the median age was 43 yrs (range 34-58 yrs) and two were smokers. Open lung biopsies were taken for diagnosis and staging of disease and not for research purposes. The clinical diagnosis of fibrosing alveolitis was confirmed histologically in all eight patients. Two patients were receiving penicillamine and one was receiving prednisolone (15 mg daily) and alpha-interferon. None was receiving azathioprine or cyclophosphamide. Biopsies were taken from the right lower lobe (RLL) $(\mathrm{n}=2)$, right middle lobe $(\mathrm{RML})(\mathrm{n}=2)$, right upper lobe (RUL) $(n=2)$, left lower lobe (LLL) $(n=1)$, left upper lobe (LUL) $(\mathrm{n}=1)$.

For comparison, samples of grossly and histologically normal peripheral lung were obtained from seven patients undergoing lobectomy for lung cancer: five males and two females, median age 71 yrs (range 35-74 yrs), of whom six were smokers. Samples were taken from peripheral uninvolved areas of the resected lobes.

\section{Study Design}

To evaluate morphological differences between FASSc patients and controls, mean numbers of immunopositive cells $\cdot \mathrm{mm}^{-1}$ alveolar wall length were calculated for each of the three antibodies in each case. The numbers of CD3+ cells were also expressed as a percentage of CD45+ cells; numbers of UCHL1+ cells were expressed as a percentage of $\mathrm{CD} 3+$ cells. The mean numbers of immunopositive cells $\cdot \mathrm{mm}^{-1}$ alveolar wall length were then compared between FASSc patients and controls. The relationship between alveolar wall thickness and the numbers of UCHL1+ cells, expressed per alveolar wall length and per alveolar wall area, was examined in 15 randomly selected fields in each of the eight patients with FASSc (i.e. a total of 120 fields).

\section{Methods}

Immunohistological examination of $10 \%$ neutral-buffered, formalin-fixed, paraffin-embedded $5 \mu \mathrm{m}$ sections was performed following application of polyclonal antiCD3 (T-cells, DAKO A452), monoclonal anti-UCHL1 (antigen-primed T-cells, DAKO M742) and monoclonal anti-CD45 (leucocyte common antigen, DAKO M701) antibodies, visualized using the alkaline phosphataseanti-alkaline phosphatase method (APAAP) reported previously [10].

The number of positively stained cells was determined by observer-interactive computerized image analysis (Improvision-Apple Mac). Colour thresholding was used a)

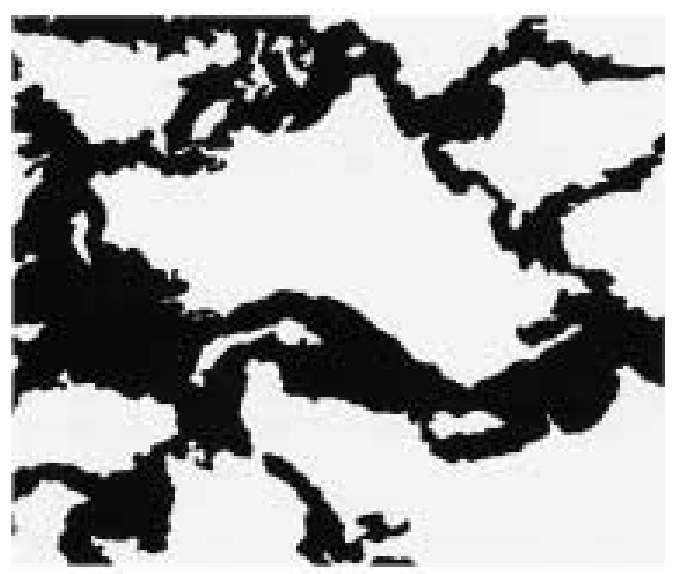

b)

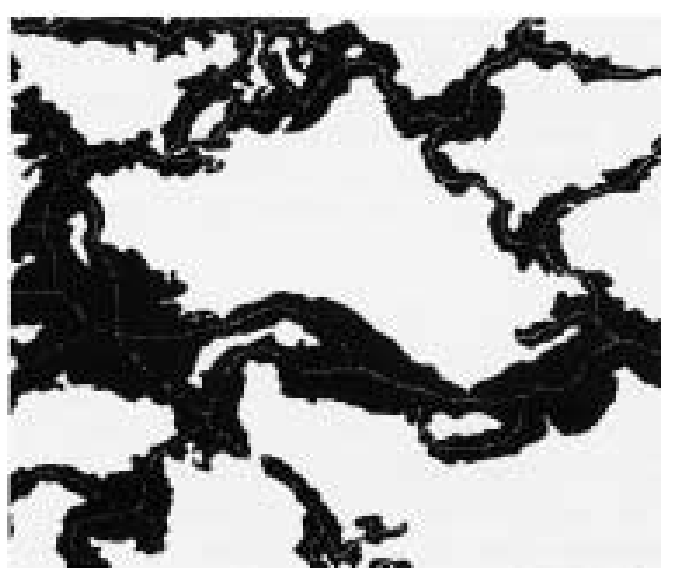

Fig. 1. - a) Computerized image of alveolar wall after "editing out" alveolar contents. b) The image as it appeared after tracing the midpoint of the alveolar wall to record its length.

to highlight interstitial tissue (fig. 1a), and the area of alveolar wall was determined after alveoli, large blood vessels, bronchioles and lymphoid tissue had been excised by means of the "edit" facility. The alveolar wall outline was traced by the interactive "mouse" facility (fig. 1b). Numbers of immunopositive cells, alveolar wall length and alveolar wall thickness (area divided by length) were assessed for each field.

To determine the numbers of fields required to accurately estimate the mean for each section, numbers of $\mathrm{CD} 3+$ cells $\cdot \mathrm{mm}^{-2}$ alveolar wall were tabulated for 10 randomly selected fields in sections from each of six patients. Estimation of the standard error of the mean within $95 \%$ confidence limits required a maximum of 63 fields, and within $90 \%$ confidence limits a maximum of 13 fields [11]; $90 \%$ confidence limits were chosen for the study. Formal scoring was then performed for each antibody in 15 randomly selected fields (objective $\times 10$ ) in one section in each case.

Interobserver variability for two observers was assessed for the measurement of numbers of immunopositive cells (CD45RO+ cells), alveolar wall area and alveolar wall length in 15 randomly selected fields (five fields 
from the sections of each of three biopsies). The coefficients of variation were $4.1,4.9$ and $12 \%$ for alveolar wall area, alveolar wall length and number of CD45$\mathrm{RO}+$ cells $\cdot$ field $^{-1}$, respectively. The main source of interobserver variability for determination of cell numbers was the disparity in the selection of threshold intensity for cell positivity.

\section{Analysis}

Mean numbers of immunopositive cells per alveolar wall length were compared between FASSc patients and controls; nonparametric analysis was performed as the distribution of the mean numbers of immunopositive cells per unit alveolar wall length showed a positive skew. For analyses of correlation, the numbers of CD45RO+ cells per alveolar wall length were logarithmically transformed to normalize the distribution and the correlations between: 1) immunopositive cells per alveolar wall length and alveolar wall thickness; and 2) immunopositive cells per alveolar wall length and alveolar wall area were examined parametrically in 120 fields. A p-value of less than 0.05 was taken to be statistically significant.

\section{Results}

Histology of the biopsy specimens of patients with FASSc demonstrated a variable mixed pattern of mural and luminal inflammation and interstitial fibrosis. Some patients showed only mild mural thickening associated with accumulations of lymphocytes in areas of focal thickening and few alveolar macrophages (fig. 2a), whereas others showed marked accumulation of alveolar macrophages (fig. 2b). Several patients showed severe mural fibrosis with loss of alveolar architecture, bronchiolization of alveoli and hyperplasia of smooth muscle. Cystically dilated spaces lined by cuboidal alveolar lining cells were often present (fig. 2c). Vessel walls were often thickened and lymphoreticular aggregates were frequently found. Control tissue showed minimal thickening of alveolar walls (fig. 2d) and, in some cases, accumulation of alveolar macrophages containing tar bodies, in keeping with cigarette smoking.

\section{Alveolar wall thickness}

Mean alveolar wall thickness was greater in FASSc patients $(60.7 \pm 24.0 \mu \mathrm{m})$ than in controls $(15.7 \pm 5.3 \mu \mathrm{m})$ $(\mathrm{p}<0.001)$.

\section{Immunohistochemical analysis}

In patients with FASSc, significant increases were observed in the numbers of $\mathrm{CD} 45+, \mathrm{CD} 3+$ and $\mathrm{CD} 45 \mathrm{RO}+$ cells $\mathrm{mm}^{-1}$ alveolar wall length (fig. 3) $(\mathrm{p}<0.01)$, and cells $\cdot \mathrm{mm}^{-2}$ alveolar wall area $(\mathrm{p}<0.05)$. Immunopositive cells were widely distributed in the lung interstitium in FASSc patients (fig. 2a and b). The majority of cells a)

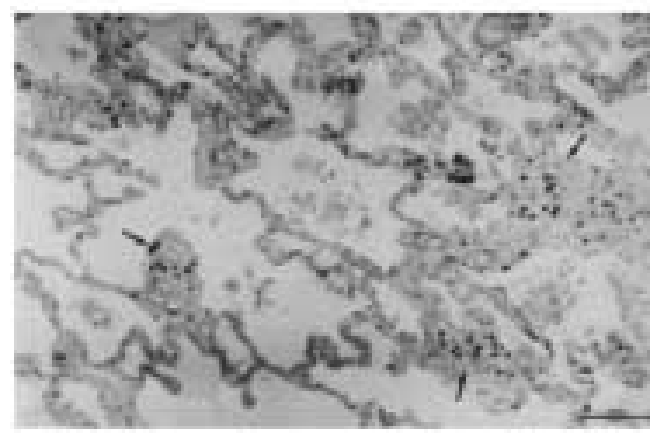

b)

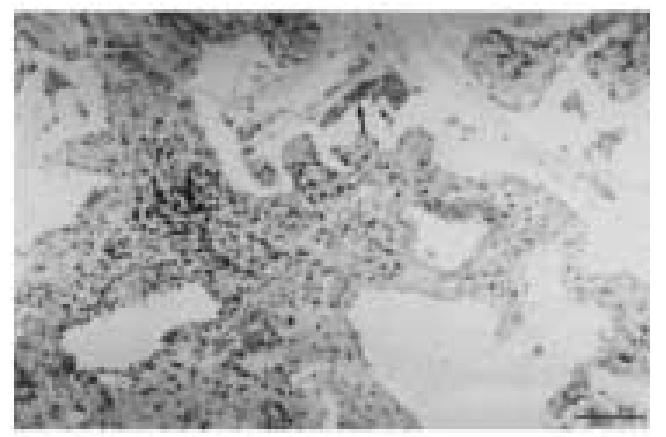

c)

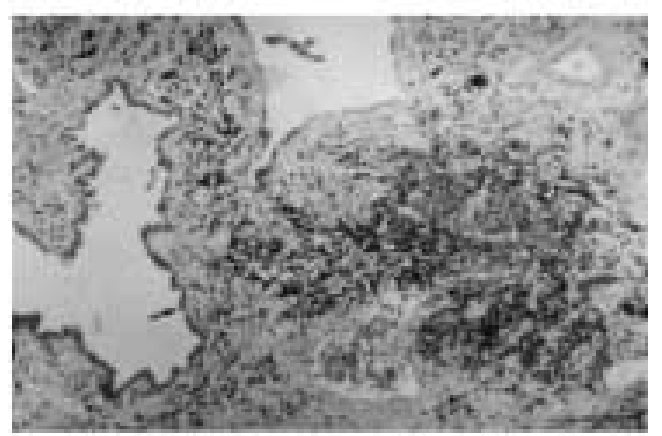

d)

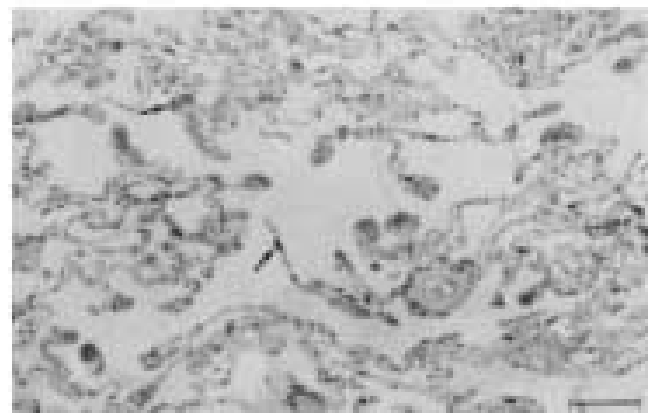

Fig. 2. - a) Light micrograph of a case of fibrosing alveolitis in systemic sclerosis (FASSc) showing minimal thickening of the alveolar wall and accumulations of $\mathrm{CD} 3+(\mathrm{T})$-lymphocytes in areas of focal thickening (arrows). b) Thickening of the alveolar wall in a patient with FASSc showing an accumulation of CD45RO+ cells. Macrophages are present in the alveolar space (arrow). c) Cystically dilated airspaces lined by cuboidal cells (black arrow). Markedly thickened wall with lymphoid follicle showing CD45RO+ cells at its periphery and a negative germinal centre (white arrow). d) Thin alveolar walls and relative sparsity of CD45RO+ cells (arrows) in a control subject. (Scale bar: $50 \mu \mathrm{m})$. 


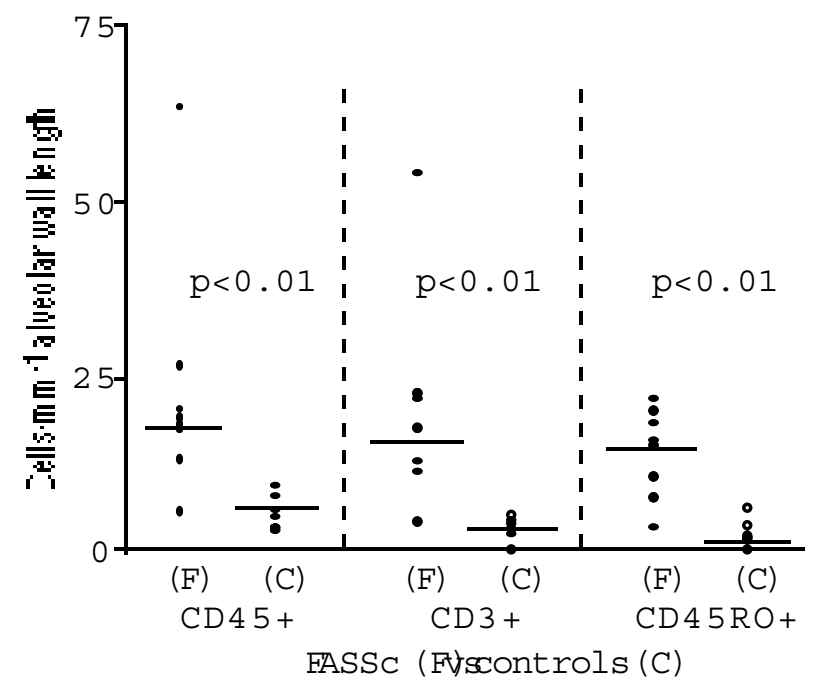

Fig. 3. - The numbers of immunopositive cells. $\mathrm{mm}^{-1}$ alveolar wall length. For each immunomarker, there was a significantly higher value in patients with fibrosing alveolitis in systemic sclerosis (FASSc) as compared with controls (C) (Mann-Whitney test). Bar indicates medi-

a)

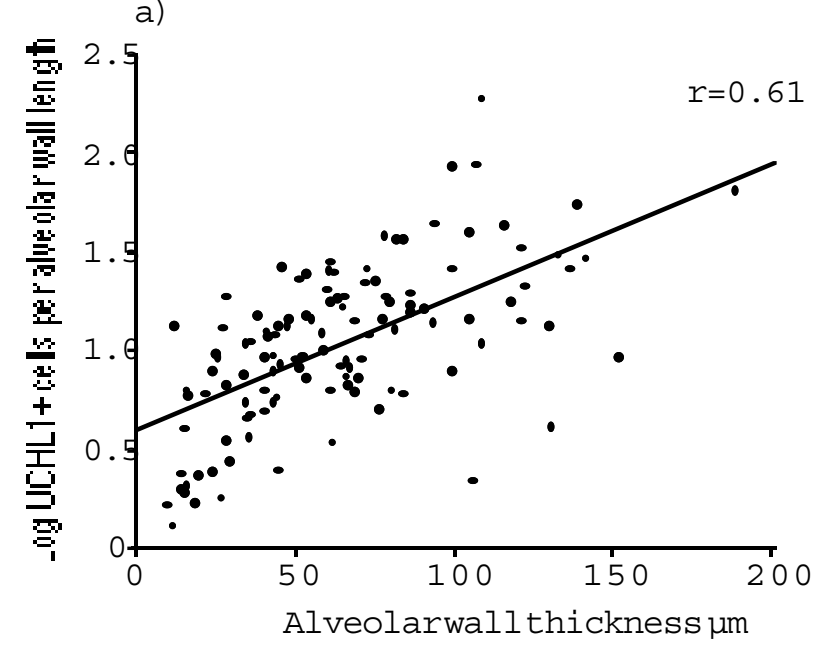

b)

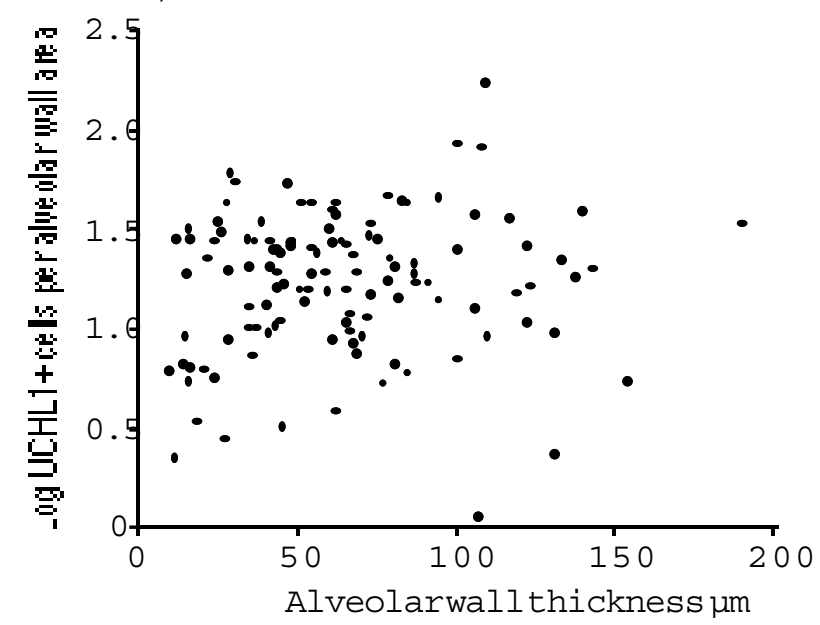

Fig. 4. - a) The association between the numbers of CD45RO+ cells per alveolar wall length and alveolar wall thickness. b) The relationship between the numbers of CD45RO+ cells per alveolar wall area and alveolar wall thickness. within lymphoid follicles (excluded from formal scoring) were CD3 and CD45RO negative; however, CD3+ and CD45RO+ cells on the edges of and immediately adjacent to lymphoid follicles were present in very high density (fig. 2c). The median value for the percentage of $\mathrm{CD} 3+$ cells which were $\mathrm{CD} 45 \mathrm{RO}+$ was $77 \%$ in systemic sclerosis compared with $36 \%$ in the control tissue. This difference did not, however, reach statistical significance (Wilcoxon rank sum test).

Numbers of primed T-cells in relation to alveolar wall thickness

Following $\log$ transformation to the base 10, the numbers of CD45RO+ cells $\cdot \mathrm{mm}^{-1}$ alveolar wall length, and cells $\cdot \mathrm{mm}^{-2}$ alveolar wall area, were evaluated in relation to alveolar wall thickness in each of the 120 fields scored in the eight patients with FASSc. There was a positive correlation between log number of CD45RO+ cells $\cdot \mathrm{mm}^{-1}$ alveolar wall length and the mean thickness of alveolar wall $(\mathrm{r}=0.61 ; \mathrm{p}<0.001)$ (fig. $4 \mathrm{a})$. However, when the number of CD45RO+ cells was related to the area of alveolar wall, the numbers remained constant with increasing alveolar wall thickness (fig. 4b), emphasizing that collagen deposition was not associated with a decline in T-cell numbers.

\section{Discussion}

The findings in the present study indicate that the interstitial infiltrate of mononuclear cells in FASSc consists largely of UCHL1 positive memory T-cells, suggesting that persistent inflammation involves cells which have an enhanced response to recall antigens which may be present locally within the lung, perpetuating the inflammatory response. Contrary to expectations, the numbers of memory T-cells per unit alveolar wall area did not decrease with the reduction in vascularity in regions of severe fibrosis, suggesting that there is a continuing signal favouring T-cell recruitment to the lung interstitium, even in advanced disease.

Immunocytochemistry has greatly facilitated the delineation of subpopulations of T-lymphocytes. It was initially assumed that surface markers defined distinct lineages of T-cells [12], but there is now much support for an alternative hypothesis proposing that selected surface markers define T-cells at different stages of maturation [13]. T-cell activation has been shown to result in a loss of CD45R positivity (defined by the presence of the 2H4 molecule) and a reciprocal gain in other markers, including CD29, CD2, lymphocyte functionassociated antigens (LFA-1 and LFA-3), PGP-1 and CD45RO (UCHL1) [5, 14-16]; these distinct markers define the same broad subset of T-cells. The numbers of UCHL1+ and CD45R+ cells are reciprocal; less than $1 \%$ of resting T-cells stain for both CD45R and UCHL1 [5]. Following antigenic re-exposure, proliferation is virtually confined to the UCHL1 + CD45R- subgroup [5]. On this basis, T-cells have been subdivided into 
functionally "naive" uncommitted CD45R+ cells and "memory" (CD45RO+) cells which have been primed by antigen and are associated with marked responsiveness to antigen re-exposure [17-19]; this subdivision applies both to the CD4+ [20] and the CD8+ [19] T-cell subsets. This subdivision may not be so clear-cut, however, and there are now increasing data to suggest that isoform switching is not unidirectional, bringing into question the concept of "naive" and "memory" subset separation on the basis of CD45 expression [6, 7]. In normal volunteers, the great majority of T-cells obtained by bronchoalveolar lavage carry the $\mathrm{CD} 45 \mathrm{RO}+$ phenotype $[21,22]$, supporting the concept that the lung functions as an active immunological organ. Judging from studies of patients with chronic beryllium disease [22] and sarcoidosis [23, 24], the same preponderance of CD45RO+ T-cells is seen with bronchoalveolar lavage fluid in diffuse interstitial lung disease; the major difference between normal subjects and patients with chronic beryllium disease lay in the far greater absolute numbers of CD45RO+ T-cells in the latter [22]. The lack of correlation between bronchoalveolar lavage and interstitial cellularity complicates the interpretation of this data. This may also explain why the proportions of CD3+ T-cells which were CD45RO+ in our study were lower than reported in studies of lavage cells. Furthermore, this raises the interesting possibility that the evolution of CD45RO positivity occurs as the cells are recruited to the epithelial lining fluid during their transition through the interstitium. Despite these quantitative differences, our findings demonstrate that the same absolute increases in CD45RO+ and other immunopositive cells, without major changes in their relative proportions are seen within lung interstitium in fibrosing alveolitis.

The intense infiltration of lung interstitium by memory $\mathrm{T}$-cells in the present study suggests that antigenic stimulation of T-cells may have a role in the ongoing chronic inflammation of FASSc, and is consistent with studies in rheumatoid arthritis and multiple sclerosis, two autoimmune disorders in which an increase in the proportion of T-lymphocytes which are memory T-cells has also been observed $[25,26]$. Studies of the T-cell antigen receptor repertoire would be needed to determine if this is an oligoclonal response, as would be expected if the T-cell response was driven by specific antigen(s).

In the present study, the numbers of memory T-cells per unit alveolar wall length increased in proportion to alveolar wall thickness, and, thus, T-cell numbers per unit alveolar wall area remained constant. This finding, applied to fields in which alveolar walls were markedly thickened by fibrosis, emphasizes that T-cell accumulation occurred even in advanced disease. If T-cell responses wane as fibrosis develops, their numbers might be expected to decline in areas of marked alveolar wall thickening, in keeping with the concomitant reduction of capillaries. The fact that memory T-cell numbers are maintained, despite a short lifespan in vivo [27] and a reduction in blood supply in severely affected regions of the lung [28], suggests that they are actively recruited, even to areas of marked fibrosis. The mechanism of recruitment and the subsequent relationship of T-cells to lung fibroblast proliferation and collagen deposition following antigen-priming and activation requires further study. One possibility is that T-cells play a role in regulating the deposition of collagen, a concept for which there is recent support from animal studies [29].

In the present study, a computerized image analysis programme was employed to quantify cell numbers, alveolar wall area and alveolar wall thickness. This method of quantification of inflammatory cell numbers in relation to alveolar wall thickness and length is time-consuming but has some advantages over semi-quantitative scoring systems evaluated and employed in earlier work [30-33]; whilst semi-quantitative systems are suitable for making observations of major differences between patient groups, they offer less precision and reproducibility. In a recent study of interobserver variability among experienced histopathologists, the kappa coefficients of agreement varied from -0.06 to 0.30 ; for most variables, agreement between observers in assigning a semi-quantitative grade was little higher than that expected by chance [30]. In another study, an eight point scale was constructed to quantify the degree of pulmonary fibrosis; however, interobserver variability was substantial (coefficient of variation greater than 30\%) [31]. In the present study, interobserver variability in the measurement of alveolar wall length and alveolar wall area was minimal (coefficients of variation less than 5\%). The interobserver variability associated with measurement of the numbers of immunopositive cells was higher than hoped (coefficient of variation $12 \%$ ) and was largely attributable to the selection of the colour cut-off used to define immunopositivity. This limitation should be borne in mind in studies demonstrating subtle differences between subgroups; however, interobserver variability was considerably lower than the differences observed between subgroups.

In conclusion, we report that most T-cells in the lung interstitium of patients with FASSc are of the memory phenotype: the numbers of these cells are maintained in the areas of greatest alveolar wall thickness, despite the associated reduction in blood supply. These findings suggest that T-lymphocytes are actively recruited to the lung, and are likely to play a part in maintaining chronic inflammation and contributing to the slow but progressive deterioration of lung function in systemic sclerosis.

\section{References}

1. Haslam PL. Evaluation of alveolitis by studies of lung biopsies. Lung 1990; 168 (Suppl.): 984-992.

2. Kradin RL, Divertie MB, Colvin RB, et al. Usual interstitial pneumonitis is a T-cell alveolitis. Clin Immunol Immunopathol 1986; 40: 224-235.

3. Crystal RG, Gadek JE, Ferrans VJ, Fulmer JD, Line BR, Hunninghake GW. Interstitial lung disease: current concepts of pathogenesis, staging and therapy. Am J Med 1981; 70: 542-568.

4. Berman JS, Beer JD, Theodore AC, Kornfeld H, Bernardo J, Center DM. Lymphocyte recruitment to the lung (State of the Art). Am Rev Respir Dis 1990; 142: 238-257.

5. Akbar AN, Terry L, Timms A, Beverley PCL, Janossy 
G. Loss of CD45R and gain of UCHL1 reactivity is a feature of primed T-cells. J Immunol 1988; 140: 21712178 .

6. Rothstein DM, Yamada A, Schlossman SF, Morimoto C. Cyclic regulation of CD45 isoform expression in a long term human CD4+ CD45RA+ T-cell line. J Immunol 1991; 146: 1175-1183.

7. Michie CA, McLean A, Alcock C, Beverley PCL. Lifespan of human lymphocyte subsets defined by CD45 isoforms. Nature 1992; 360: 264-265.

8. Harrison NK, Myers R, Corrin B, et al. Structural features of interstitial lung disease in systemic sclerosis. $\mathrm{Am}$ Rev Respir Dis 1991; 144: 706-713.

9. Subcommittee for Scleroderma Criteria of the American Rheumatism Association Diagnostic and Therapeutic Committee. Preliminary criteria for the classification of systemic sclerosis (scleroderma). Arthritis Rheum 1980; 23: 581-590.

10. Azzawi M, Johnston PW, Majumdar S, Kay AB, Jeffery PK. T-lymphocytes and activated eosinophils in airway mucosa in fatal asthma and cystic fibrosis. Am Rev Respir Dis 1992; 145: 1477-1482.

11. Aherne WA, Dunnill MS. In: Morphometry. London, Edward Arnold Ltd, 1982.

12. Dalchau R, Fabre JW. Identification with a monoclonal antibody of a predominantly B-lymphocytespecific determinant of the human leukocyte common antigen: evidence for structural and possible functional diversity of the human leukocyte common molecule. $J$ Exp Med 1981; 153: 753-765.

13. Tedder TF, Cooper MD, Clement LT. Human lymphocyte differentiation antigens HB-10 and HB-11: differential production of B-cell growth and differentiation factors by distinct helper T-cell subpopulations. J Immunol 1985; 134: 2989-2994.

14. Smith SH, Brown MH, Rowe D, Callard RE, Beverley PCL. Functional subsets of human helper-inducer cells defined by a new monoclonal antibody, UCHL1. Immunology 1986; 58: 63-70.

15. Sanders ME, Makgoba MW, Sharrow SO, et al. Human memory T-lymphocytes express increased levels of three cell adhesion molecules (LFA-3, CD2, and LFA-1) and three other molecules (UCHL1, CDw29, and PGP-1) and have enhanced IFN- $\gamma$ production. J Immunol 1988; 140 1401-1407.

16. Serra HM, Krowka JF, Ledbetter JA, Pilarski LM. Loss of CD45R (Lp220) represents a post-thymic T-cell differentiation event. J Immunol 1988; 140: 1435-1441.

17. Sanders ME, Makgoba MW, Shaw S. Human naive and memory T-cells: reinterpretation of helper-inducer and suppressor-inducer subsets. Immunology Today 1988; 9: 195-199.

18. Plebanski M, Saunders M, Burtles SS, Crowe S, Hooper DC. Primary and secondary human in vitro T-cell responses to soluble antigens are mediated by subsets bearing different CD45 isoforms. Immunology 1992; 75: 8691.

19. Akbar AN, Amlot PL, Timms A, Lombardi G, Lechler
R, Janossy G. The development of primed/memory CD8+ lymphocytes in vitro and in rejecting kidneys after transplantation. Clin Exp Immunol 1990; 81: 225-231.

20. Yamashita N, Bullington R, Clement LT. Equivalent helper functions of human "naive" and "memory" CD4+ T-cells for the generation of alloreactive cytotoxic Tlymphocytes. J Clin Immunol 1990; 10: 237-246.

21. Becker S, Harris DT, Koren HS. Characterization of normal human lung lymphocytes and interleukin-2-induced lung T-cell lines. Am J Respir Cell Mol Biol 1990; 3: $441-448$.

22. Saltini C, Kirby M, Trapnell BC, Tamura N, Crystal RG. Biased accumulation of T-lymphocytes with "memory" -type CD45 leukocyte common antigen gene expression on the epithelial surface of the human lung. J Exp Med 1990; 171: 1123-1140.

23. Dominique S, Bouchonnet F, Smiejan JM, Hance AJ. Expression of surface antigens distinguishing "naive" and previously activated lymphocytes in bronchoalveolar lavage fluid. Thorax 1990; 45: 391-396.

24. du Bois RM, Kirby M, Balbi B, Saltini C, Crystal RG. T-lymphocytes that accumulate in the lung in sarcoidosis have evidence of recent stimulation of the T-cell antigen receptor. Am Rev Respir Dis 1992; 145: 1205-1211.

25. Emery P, Gentry KC, Mackay IR, Muirden KD, Rowley M. Deficiency of the suppressor inducer subset of Tlymphocytes in rheumatoid arthritis. Arthritis Rheum 1987; 316: 849-856.

26. Morimoto C, Hafler DA, Weiner HL, et al. Selective loss of the suppressor-inducer T-cell subset in progressive multiple sclerosis: analysis with anti-2H4 monoclonal antibody. $N$ Engl J Med 1987; 316: 67-72.

27. Beverley PC. Functional analysis of human T-cell subsets defined by CD45 isoform expression. Sem Immunol 1992; 4: 35-41.

28. Crystal RG, Gadek JE, Ferrans VJ, Fulmer JD, Line BR, Hunninghake GW. Idiopathic pulmonary fibrosis: clinical, histologic, radiographic, physiologic, scintigraphic, cytologic and biochemical aspects. Ann Intern Med 1976; 85: 769-788.

29. Kimura R, Hu H, Stein-Streilein J. Delayed-type hypersensitivity responses regulate collagen deposition in the lung. Immunology 1992; 77: 550-555.

30. Cherniak RM, Colby TV, Flint A, et al. and the BAL Co-operative Group Steering Committee. Quantitative assessment of lung pathology in idiopathic pulmonary fibrosis. Am Rev Respir Dis 1991; 144: 892-900.

31. Ashcroft T, Simpson JM, Timbrell V. Simple method of estimating severity of pulmonary fibrosis on a numerical scale. J Clin Pathol 1988; 41: 467-470.

32. Watters LC, Schwarz MI, Cherniak RM, et al. Idiopathic pulmonary fibrosis: pretreatment bronchoalveolar lavage cellular constituents and their relationships with lung histopathology and clinical response to therapy. Am Rev Respir Dis 1987; 135: 696-704.

33. Gaensler EA, Carrington CB, Coutu RE, et al. Radiologic, physiologic, pathologic correlations in pneumoconiosis. Ann NY Acad Sci 1972; 200: 574-607. 